\title{
HOW ULTRASONOGRAPHIC GUIDED THORACENTESIS SCORES OVER BLIND PROCEDURES?
}

Bharat Bhushan Sharma, Sagar Garg, Abhivind Bhutani, Mir Rizwan Aziz, Monu Sarin, Gagan Chauhan, Surabhi Lathwal, Manpreet Kaur

\begin{abstract}
Thoracentesis is tapping of pleural fluid from the pleural cavity for either diagnostic or therapeutic purposes. These are the frequently encountered procedures in the medical practices. Many conditions warrant sending the cases of pleural effusion cases for intervention. Most of the cases had been tried blindly first in their respective departments but failed because of various reasons. It had been documented regarding the advantages and disadvantages of blind and ultrasonography (USG) guided procedures. The aim of the study was to highlight the advantages and benefits of USG guided thoracentesis. We carried out USG guided thoracentesis of fifty cases in our radiology section who were referred to us by various departments. There were 19 female (38\%) and 31 male (62\%) patients. All these candidates had failed in blind procedures, when tried first. All these cases underwent USG guided thoracentesis with almost negligible complications. These were found to be having pleural fluid collection due to different underlying pathologies. There was no major complication in any of the cases who underwent thoracentesis. We reiterate by this study that USG guided procedures in thoracentesis should be the first choice in the tapping of pleural fluid. This is a quick, affordable, and without any discomfort to the patient.
\end{abstract}

\section{KEYWORDS}

Thoracentesis, pleural fluid, pleural cavity, ultrasonography

\section{CORRESPONDING AUTHOR}

Bharat Bhushan Sharma,

Professor \& HOD, Department of Radio-diagnosis, SGT Medical College Budhera (Gurugram), A 6/7, First Floor, Vasant Vihar, New Delhi - 110057

Email: bbhushan986@gmail.com

Orcid No: https://orcid.org/0000-0002-1311-2349

DOI: https://doi.org/10.3126/nmcj.v23i3.35317 


\section{INTRODUCTION}

Pleural aspiration (thoracocentesis) and chest needle insertion may be required in many different clinical settings for a variety of indications. This is frequently required and asked for in the daily medical practice. ${ }^{1}$ The prevalence of pleural effusion in the intensive care units can vary between $40 \%$ to $60 \%$. There is a need for interventions in these type of cases for either diagnostic or therapeutic purposes. ${ }^{2}$ The most common causes of pleural effusion in our population are infectious exudates (43\%), non-infectious exudates (33\%), and transudates $(24 \%),{ }^{3}$ The most common cause of pleural effusion is due to hemothorax (7\%) which is found among those patients who undergo cardiac surgery. Dyspnoea is the most common symptom among these patients. ${ }^{4}$ There is an evidence of more danger of complications by attempting the procedures with wide-bore needles.

Small bore needles with the Seldinger technique also are not without any serious complications. ${ }^{5}$ The use of blind technique is especially associated with higher complications (18\% of cases). ${ }^{6}$ So in these settings, USG guided needle aspiration is well versed and handy technique to reduce complications. The aim of this study was to evaluate the success of USG guided thoracocentesis in patients in which blind technique was not successful and to determine the prevalence of complications in these patients following this procedure.
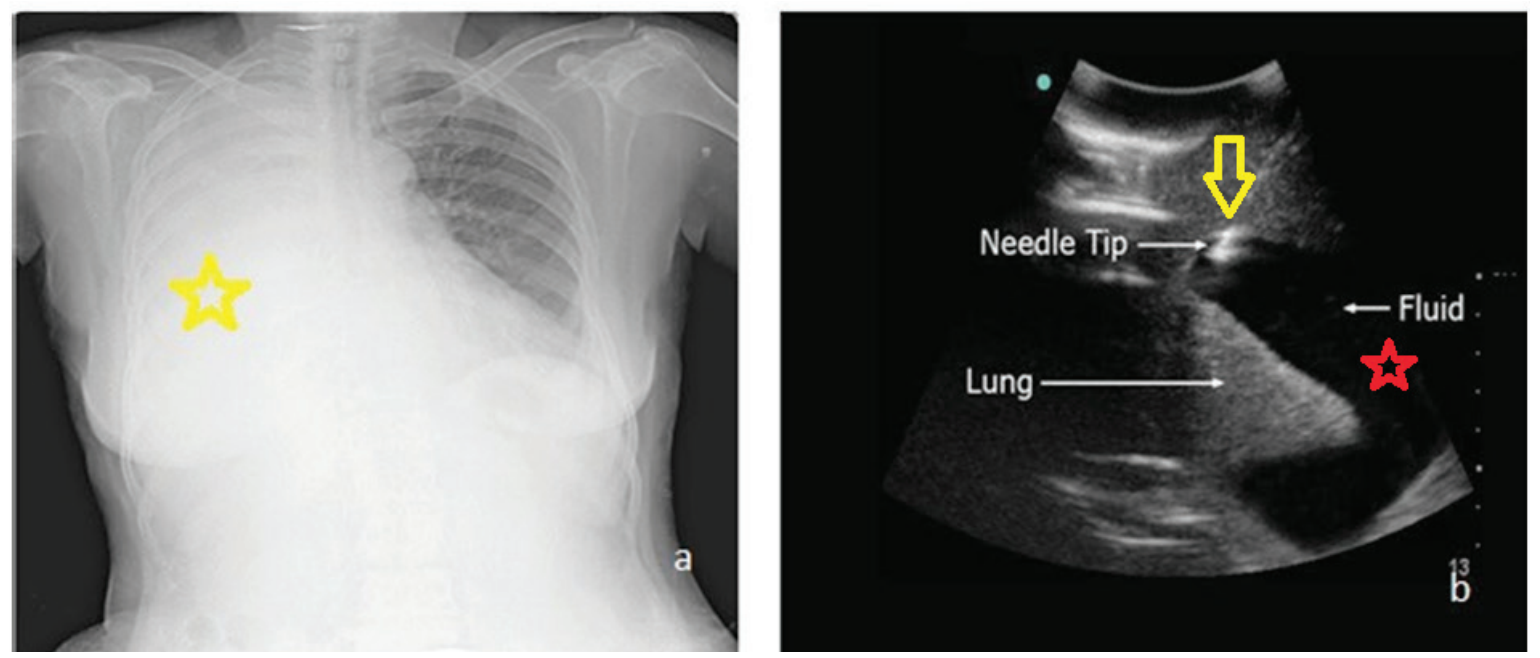

Fig. 1: Chest X-ray and Ultrasound of 40-year old female patient .a).Posteroanterior chest

radiograph with massive pleural effusion on right side (yellow star).b) USG chest depicting anechoic region on right side as pleural effusion (red star) and the echogenic needle tip (inverted yellow arrow) seen during intervention
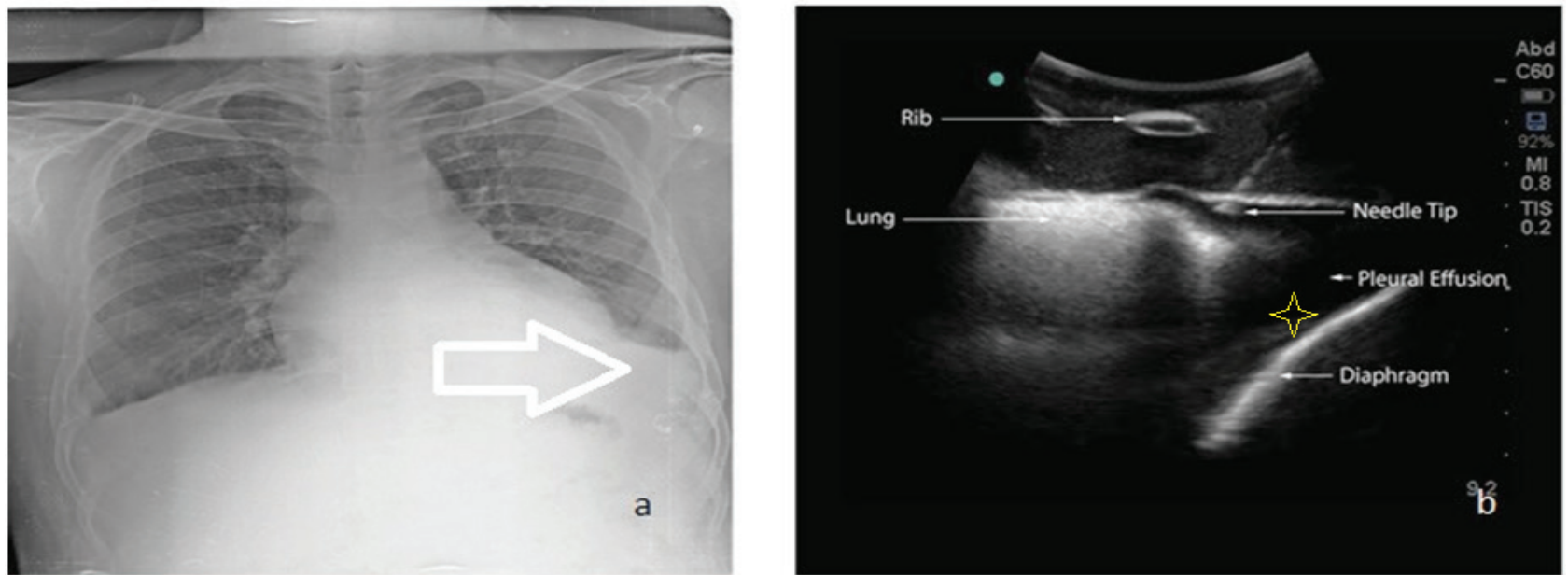

Fig. 2: Chest X-ray and Ultrasound of 32-year old male with unexplained fever.a) Posteroanterior chest radiograph with minimal pleural effusion (white arrow).b) USG chest showing left costophrenic angle (CP) having minimum anechoic region as pleural effusion (yellow star). The ultrasound guided diagnostic tap was made as blind procedure failed. 

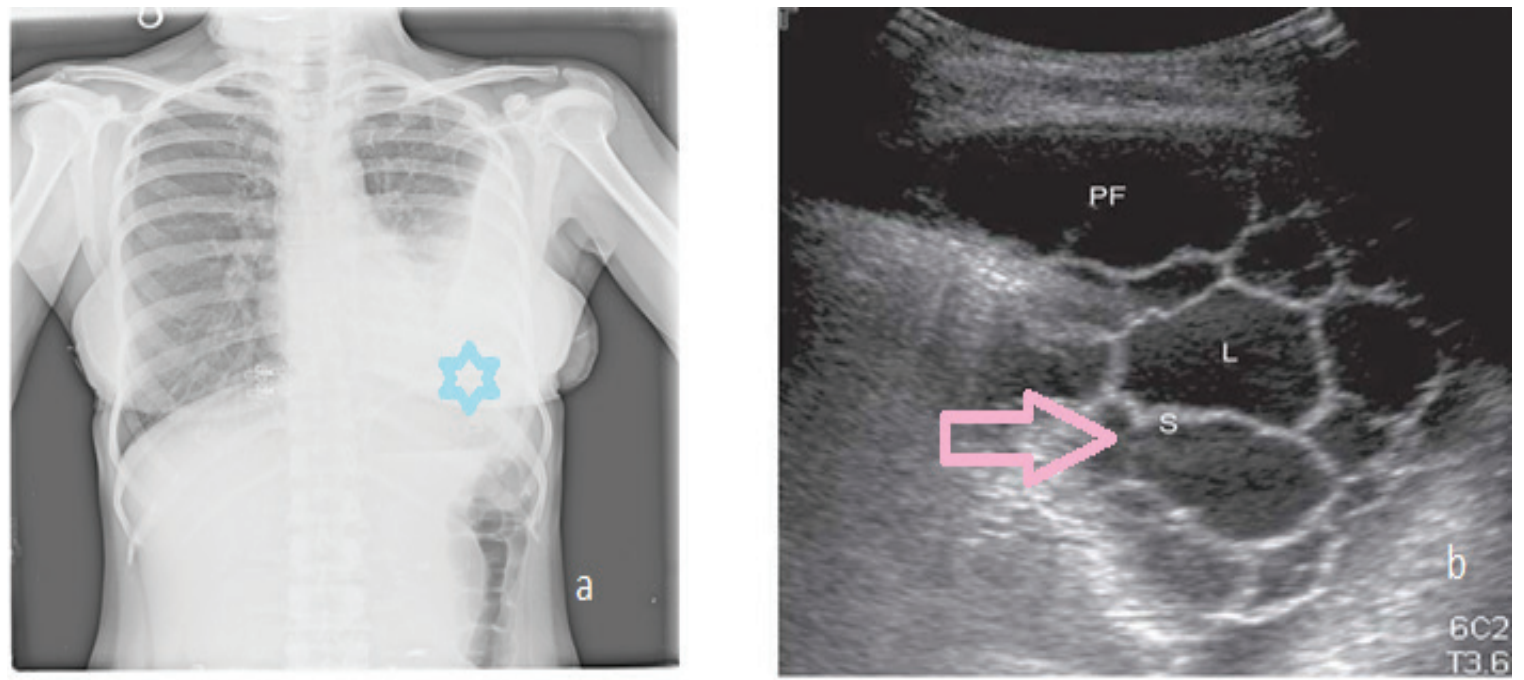

Fig. 3: Chest Xray and Ultrasound of 60-year old female with underlying heart ailment. a) posteroanterior chest radiograph with obliterated opaque left costophrenic angle (blue star).

b) USG chest of left CP angle which show encysted pleural effusion with multiple septations (pink arrow).

\section{MATERIAL AND METHODS}

The study was conducted in the SGT Medical College and Hospital. A prospective study was carried out on 50 patient referred for USG guided throacocentesis to the radiology department of SGT Medical College. In most of the cases the procedure was elective and diagnostic. There was19 female (38\%) and 31 males (62\%) patients. The age group included 23 years to 65 years (average 41 years). Pleural aspiration was done in the clear area under full aseptic radiologist. Lidocaine $1 \%$ is infiltrated locally prior to the procedure. One takes particular attention to the skin, periostium and the pleura during the procedure. The volume can be calculated by ultrasound if there are many small pockets as all dimensions can be visualized.An 18 bore needle is inserted via skin after local antisepsis. A lumbar puncture needle is used in cases where the depth of pleural effusion is more than $15 \mathrm{~mm}$ from the skin. The needle is

\section{Table 1: Distribution of the patients as per the tapping of the amount of pleural fluid}

$\begin{array}{|lcccc|}\text { Volume of fluid tapped } & \text { Less than } \mathbf{3 0} \mathbf{~ m l} & \mathbf{3 0 - 5 0} \mathbf{~ m l} & \mathbf{5 0 - \mathbf { 1 0 0 }} \mathbf{~ m l} & \text { More than } \mathbf{1 0 0} \mathbf{~ m l} \\ \text { No. Of patients } & 12 & 9 & 22 & 7\end{array}$

conditions. All these procedures were done as elective procedures. Patients with normal International Normalized Ratio (INR) were selected. No one was taking any anticoagulants. The patient was made to lie down and volume of fluid was obtained by using a method developed by Bailik et al. Then the patient is made to sit straight with the back facing the guided by USG all throughout the procedure, In the intercostal space we go above the lower rib so as to avoid nerve or vessel injury. Then syringe suction is done. After desired fluid is obtained wound is closed by an aseptic procedure. When the amount of pleural fluid collection is reasonably more, fluid can be aspirated without any complications (Fig. 1).

Table 2: Distribution of the patients as per underlying cause of pleural effusion after the cytological confirmation

\begin{tabular}{|lcccc|}
\hline Diagnosis & Tuberculosis & $\begin{array}{c}\text { Other infections } \\
\text { (including fungal infections) }\end{array}$ & $\begin{array}{c}\text { Transudate ie } \\
\text { venous extrusion }\end{array}$ & Tumor \\
No. Of patients & 22 & 12 & 14 & 2 \\
\hline
\end{tabular}


The problem comes when there is minimal pleural fluid collection. The diagnostic tap is very accurate which can only be targeted with the help of sonographiic examination (Fig. 2). Ultrasound guidance is of utmost importance when the pleural fluid collection is with multiple septations.USG guidance is the gold standard in drainage of these types of loculated fluid collections (Fig. 3). The proper consent of all the patients were take and there were no ethical issue involved.

\section{RESULTS}

In all the 50 patients that were taken, throacocentesis was performed successfully for all the cases. In no cases there were any long term complications. Patients felt pain for only few minutes. There was no afterprocedural complication encountered in these cases. The procedure was quite convenient and acceptable as many procedures were carried out in ICU. The tap was diagnostic in nature in the majority of the cases. However, in seven cases, more than $100 \mathrm{ml}$ of fluid was removed and that was even therapeutic as it helped recoil of lung (Table 1). The details of cytological analysis had shown that 22 (44\%) were tubercular in origin. There were 14 (28\%) case of transudate in nature (Table2).

\section{DISCUSSION}

Pleural fluid is collected in excess due to various factors. The patients are evaluated on the grounds of the symptomatology. Thoracentesis is used for both diagnostic as well as therapeutic purposes. The most common method used to tap the pleural fluid was developed by Bailik et al. ${ }^{7-10}$ The procedure is always carried out with local anaesthesia with $1 \%$ lidocaine. The skin is made antiseptic and special attention is given to the periosteum and pleura during the procedures. ${ }^{11}$ Pleural effusion can either be exudative or transudate.

Patients are symptomatic with dyspnoea when excessive pleural fluid collections are encountered. The background reason could be because of transudative or exudative. The drainage of this excessive fluid leads to improve the breathing. ${ }^{12}$

USG guided procedures are very safe as the blind procrdures lead to many complications like hemothorax, pneumothorax and spreading the infection. ${ }^{13}$ The risk of pneumothorax is quite high $(18 \%)$ in these cases. ${ }^{6}$ On the other hand
USG guided throacocentesis also encounter problems like failure of puncture with untrained hands. USG remain totally operator dependent for these type of procedures. ${ }^{14}$ In our study, a high rate of success was achieved using USG guided throacocentesis. The difficulty was encountered with thin bore needles when thick bore needles were not used. The majority of the procedures were diagnostic in nature. A longer one like lumbar puncture needles under USG guidance were with almost total success. In 21 cases, the pleural effusion on was localized and volume was less; about $40-50 \mathrm{ml}$. It was difficult to perform a diagnostic tap in such small volume, however, it was easily tapped under USG guidance.

Pleural fluid in cases of tumors and tuberculosis was thick because of proteinaceous contents. Multiple septations take place in these cases and the exact volume is shown as false ${ }^{15}$ as we have shown in our third case (Fig 3). USG helped to guide the needle to largest pocket and take diagnostic fluid .In some cases multiple pockets could be assessed from different location and therapeutic tap was done. In one case the parietal pleura was thick and calcified. USG helped to avoid calcified pleura and guided the needle to reach the fluid avoiding it. Other advantage of USG guided procedure was to know the distance of fluid from the skin so that the exact approach and distance can be calculated.USG helps in negotiating the needle as per the calculations and targeting the site without any complications. This was very helpful in avoiding the lung puncture resulting in to pneumothorax

USG guided throacocentesis is a highly efficient, safe and minimally invasive technique. It offers high rate of success and low rate of complications especially for thin bore needle and in diagnostic procedure. It's easy availability and low cost makes it ideal for treatment and diagnosis of pleural effusion both transudative and exudative.

\section{ACKNOWLEDGEMENT}

We sincerely thank our data operator Mr. Brijesh Kumar and radiographers Miss Tusharika and Miss Shilpi for providing the desired output.

Conflict of interest: None

Source of research fund: None 


\section{REFERENCES}

1. Nishida O, Arellano R, Cheng DC, DeMajo W, Kavanagh BP. Gas exchange and hemodynamics in experimental pleural effusion. Crit Care Med 1999; 27: 583-7.

2. Mattison LE, Coppage L, Alderman DF, Herlong JO, Salm SA. Pleural effusions in the medical ICU:prevalence, causes and clinical implications. Chest 1997; 111: 1018-23

3. Fartoukh M, Azoulay E, Galliot R et al. Clinically documented pleural effusions in medical ICU patients: how useful is routine thoracentesis? Chest 2002; 121: 178-84.

4. Labidi M, Baillot R, Dionne B, Lacasse Y, Maltais F, Boulet LP. Pleural effusions following cardiac surgery: prevalence, risk factors, and clinical features. Chest 2009; 136: 1604-11.

5. Assouad J, Barthes FP, Shaker W, Souilamas R.Riquet M. Recurrent pleural effusion complicating liver cirrhosis. Amm Thorac Surg 2003; 75: 986-9. Doi: 10.1016/S00034975(02)04548-4.

6. Pignotti MS, Messeri A, Donzelli G. Thoracentesis in pericardial and pleural effusion caused by central venous catheterization: a less invasive neonatal approach. Paediatr Anaesth 2004; 14: 349-51. Doi:10:1046/j.1460-9592.2003.01225.x.

7. Bhuniya S, Arunabha DC, Chaudhary S, Saha I, Roy TS, Saha M. Role of therapeutic thoracentesis in tuberculous pleural effusion. Ann Thorac Med 2012; 7: 215-9. Doi:10.4103/1817-1737.102176.

8. Lazarev SM, Reshetov AV, Kakysheva OE, Nikolaev GV, Kirillov Iuv, Volgin GN. The assessment of surgical treatment of patients with malignant pleural effusion.Vestn Khir Im II Grek 2013; 172: 32-8.
9. Miraglia R, Maruzzelli L, Piazza M et al. Realtime ultrasound-guided placement of a pigtail catheter in supine position for draining pleural effusion in pediatric patients who have undergone liver transplantation. Clin Ultrasound 2015; 44: 284-9. Doi:10.1002/jcu.22294.

10. Marchetti G, Valsecchi A, Indellicati D, Arondi S, Trigiani M, Pinelli V. Ultrasound-guided medical thoracoscopy in the absence of pleural effusion. Chest 2015; 147: 1008-12. Doi: 10.1378/ chest.14-0637.

11. Havelock T, Teoh R, Laws D, Gleeson F. Pleural procedures and thoracic ultrasound:British Thoracic Society pleural disease guidelines. Thorax 2010; 65(Suppl 2): ii61-ii76. Doi: 10.1136/ thx.2010.137026

12. Harris A, O’Driscoll B, Turkington P. Survey of major complications of intercostals chest drain insertion in the UK. Postgrad Med J 2010; 86: 6872.

13. Krumhaar D. Dangers and errors in pleural puncture and placing suction drainage. Langenbecks Arch Chir Suppl II Verh Dtsch Ges Chir 1989; 191-4.

14. Cavanna L, Mordenti P, Berte R et al. Ultrasound guidance reduces pneumothorax rate and improves safety of thoracentesis in malignant pleural effusion: report on 445 consecutive patients with advanced cancer. World J Surg Oncol 2014; 12; 139. Doi: 10.1186/1477-7819-12139.

15. Lima DRR, Yepes AF, Jimenez CIB, Diaz MAM, Rojas DIP. Real-time ultrasoundguided thoracentesis in the intensive careunit:prevalence of mechanical complications. Ultrasound J 2020; 12: 25. Doi: org/10.1186/ s13089-020-00172-9

\title{
ERRATA
}

In the title page of article entitled 'Evaluation of direct chest circumference measurement as an efficient tool in the reduction of radiation dose in Multi-Slice Computerized Tomography of Chest- A suggestion for Radiographers' which is the page number 87 of Nepal Medical College Journal (published in June 2021 issue of NMCJ), the sequence of authors have been changed as requested by the authors.

\section{EVALUATION OF DIRECT CHEST CIRCUMFERENCE MEASUREMENT AS AN EFFICIENT TOOL IN THE REDUCTION OF RADIATION DOSE IN MULTI-SLICE COMPUTERIZED TOMOGRAPHY OF CHEST- A SUGGESTION FOR RADIOGRAPHERS}

\author{
Nitish Virmani, ${ }^{1}$ Navreet Boora, ${ }^{2}$ Mir Rizwan Aziz, ${ }^{3}$ Arshad Alam Khan, ${ }^{4}$ Natasha Nargotra, ${ }^{3}$ \\ Rohit Sharma, ${ }^{3}$ Abhivind Bhutani, ${ }^{3}$ Bharat Bhushan Sharma ${ }^{3}$
}

${ }^{1}$ Department of Radio-Diagnosis, Faculty of Allied Health Sciences, SGT University Budhera (Gurugram) 122505, ${ }^{2}$ College of Paramedical Sciences, Teerthanker Mahaveer University, Moradabad, Uttar Pradesh, India, ${ }^{3}$ Department of Radio-Diagnosis, SGT Medical College Budhera (Gurugram), ${ }^{4}$ Faculty Of Allied Health Sciences, SGT University, Gurugram, Haryana, India 